\title{
Development and protection challenges of the Syrian refugee crisis
}

\author{
Roger Zetter and Héloïse Ruaudel
}

The Syria Regional Response Plan 6 (RRP6) 2014 provides an increased focus on early recovery, social cohesion interventions and a transition from assistance to development-led interventions, alongside the continuing large-scale humanitarian assistance and protection programme.

In a region already hosting millions of Palestinian and Iraqi refugees, the scale of the Syrian crisis is putting immense additional strains on the resources and capacities of neighbouring countries and the international humanitarian system. The 3,300 refugees on average arriving in neighbouring countries every day in 2014 place a large burden on the protection capacity of the host countries and international actors and further accentuate the already severe negative social, economic and human developmental impacts on the host countries of the region. With no prospects of the civil war abating in Syria and with a peace process that might encourage refugee return even further away, the displacement is becoming protracted.

The Regional Response Plan 6 (RRP6) 2014 targets assistance to a projected year-end total of 2.85 million Syrian refugees in Jordan, Lebanon and Iraq collectively - the three countries where the three-year Regional Development and Protection Programme (RDPP) $)^{1}$ is to be implemented - and 2.5 million of the 45 million host populations. This article is based on a mapping and metaanalysis, done for the RDPP, of project evaluations, situation reports and other studies produced by intergovernmental agencies, host governments, donors and humanitarian agencies in $2013 .^{2}$

\section{Economic impacts on refugees and their livelihoods}

For refugee households, income-generating activities are scarce and for most of them the income-expenditure gap is substantial and increasing. Livelihood sustainability, cost of living and rent levels, alongside food insecurity and increasing indebtedness, are major concerns for the refugees as well as for their hosts.

Syrian refugees find casual, irregular and predominantly unskilled work when they can; across Lebanon, Jordan and Iraq about $30 \%$ of the working-age refugee population are in some form of paid, sporadic employment but, with high competition for work, wage levels are declining. That the majority of refugees live in urban areas is a significant factor since they are more able to engage in economic activity than encamped refugees. However, the opportunities are extremely limited and the livelihood vulnerability of the urban refugees is no less severe than of those in camps.

Whilst refugee registration gives access to humanitarian assistance and some public services, the Syrian refugees have no legal entitlement to work in Jordan or Lebanon without a work permit. Thus it is the informal sector which provides the opportunities for income generation but wages are inevitably very low and working conditions are exploitative. By contrast, Syrian refugees with residency rights in the Kurdish Region of Iraq are entitled to work. Evidence indicates that their livelihood conditions are less stark, although more refugees are encamped than in Jordan for example and are thus possibly better able to access humanitarian assistance.

Syrian refugees deploy a variety of highly risky coping strategies. The sale of personal assets is extensive; this not only increases their current impoverishment but depletes the resources that the refugees might have available when and if they return to Syria 
to rebuild their lives and livelihoods. Lack of employment has disproportionately affected women and youth; conversely, the rising incidence of child labour, as refugee households succumb to increasing impoverishment, is of particular concern in terms of their immediate well-being and, in the longer term, the loss of education that will affect their life chances both in exile and when they return to Syria.

The overall picture, then, is one of chronic vulnerability which is both deepening and becoming more entrenched. Whilst, inevitably, the humanitarian focus is on Syrian refugees, the situation of Palestine and Iraqi refugees secondarily displaced from Syria is extremely serious. The costs and impacts of displacement on their livelihoods are severe and their marginalisation from the mainstream response programme is particularly worrying.

\section{Economic impacts on host countries and populations}

In terms of micro-economic impacts, housing rent levels are rising steeply, pricing the local population out of the market. Substantial spikes in unemployment, depressed wage rates and limited employment opportunities, mainly for low-skilled labour, are widespread. Despite the official restrictions on working, some refugees gain employment and the surge in labour supply has deeply affected labour markets, increasing market prices for basic commodities. While cash transfers/ vouchers to assist refugees have enhanced their purchasing power it causes prices to rise in local markets, accentuating the livelihood vulnerability of an increasingly large number of local households.

As well as the fiscal stress created, the impacts on economic production and output are also severely affecting the host populations, impoverishing a very substantial number of (mainly low-income and already poor) households. Even before the crisis $25 \%$ of the Lebanese population lived below the upper poverty line of US $\$ 4$ per day and the influx of refugees was projected to push an additional 170,000 Lebanese into poverty and to double unemployment to above $20 \%$ by $2014 .^{3}$ The fact that 2.5 million people in the host countries are projected to receive assistance under RRP6 in 2014, through a range of Community Support Projects and other interventions, is indicative of this stress. Yet this accounts for little more than $5 \%$ of the three countries' combined population (about $20 \%$ in the case of Jordan and Lebanon) and is unlikely to significantly reduce either the short- or long-term negative impacts which the host communities are experiencing.

The crisis has also had a very detrimental impact on all the public services - notably the health and education sectors - alongside severe impacts on services such as water supply and power. Pre-existing substantial shortfalls in capacity have increased dramatically, despite the assistance from the Regional Response Programme to support infrastructure development.

Negative macro-economic impacts include large losses in terms of economic performance, public revenue and taxes, profits, private consumption and investment, cuts in growth, increasing unemployment and widening of the national deficits. For example, the World Bank estimated that the impact of the crisis reduced Lebanon's economic growth rate (GDP) by $2.9 \%$ per annum from a predicted growth rate of $4.4 \%$ in 2012-14, whilst foreign direct investment was projected to diminish by more than half compared to previous years. The cumulative impact has depressed government revenue by US $\$ 1.5$ billion, while simultaneously increasing government expenditure by US $\$ 1.1$ billion with the growth in demand for public services. ${ }^{4}$

There has been severe disruption to regional trading patterns and dynamics affecting import and export performance and commodity prices for consumers. The longterm dislocation of international trade will further exacerbate declining investment, rising unemployment, and commodity shortages in the region. The unstable political and security situation and spillover effects generated by the conflict reduce 
September 2014

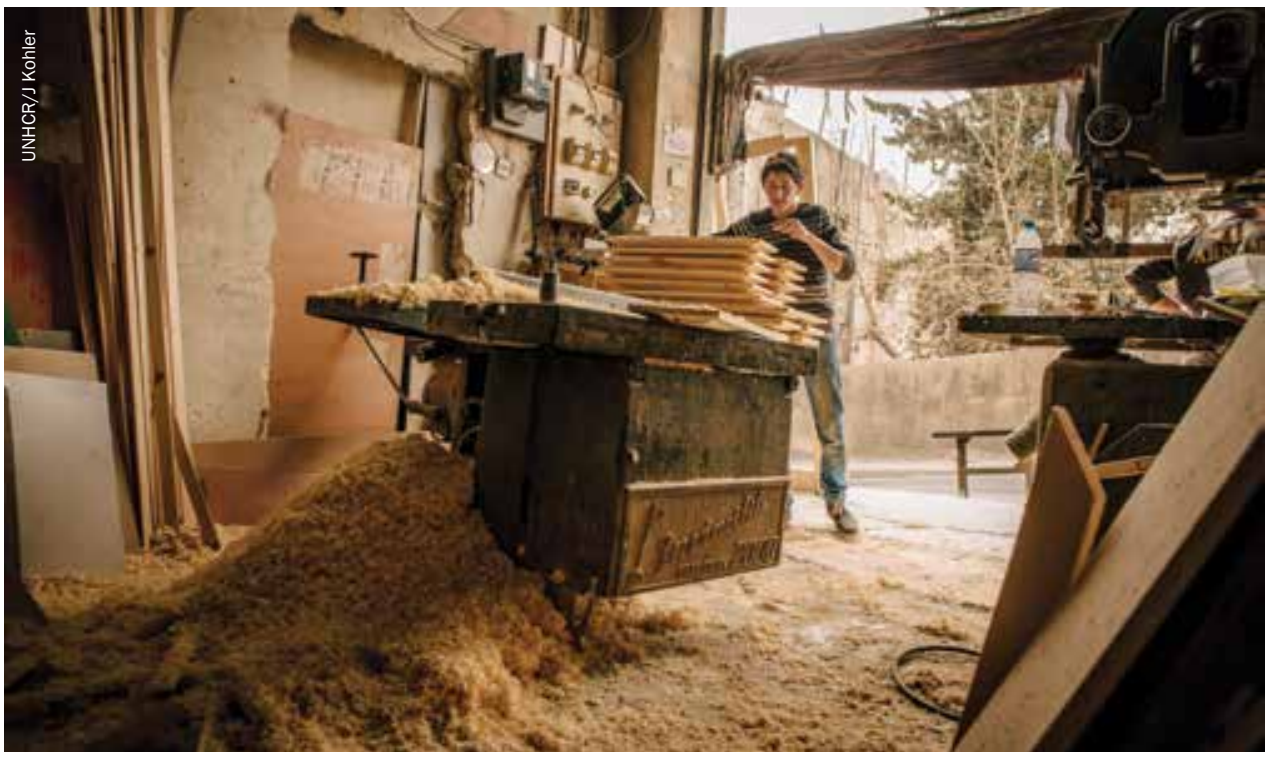

Omar, 20, works as an assistant in a carpentry shop in Amman, Jordan, to support his mother, sister and three brothers. His monthly salary covers the cost of rent. He lost his father, who taught him carpentry, to a sniper's bullet in Syria in early 2014.

investor and consumer confidence, further diminishing economic activity and placing public finances under increasing pressure.

Conversely, and maybe less commonly recognised, humanitarian crises can spark development opportunities ${ }^{5}$ and positive effects have also been reported in the region: increased availability of cheap labour which favours employers; rising demand and consumption by refugees; and benefits for large-scale agricultural producers, landlords, local traders, businesses and retailers, construction contractors, as well as suppliers of goods and commodities to the humanitarian programme. In some locations, educated refugee professionals such as engineers, doctors and skilled construction and craft workers have augmented local economic capacity. Exports from Lebanon to Syria have increased significantly, and for the first time Lebanon has a positive trade balance with Syria.

\section{The limits to refugee protection}

Although Lebanon, Iraq and Jordan are not signatories to the 1951 Refugee
Convention or its 1967 Protocol, they have displayed remarkable solidarity towards the refugee population. But an increasingly ambivalent hospitality amongst the host countries and their populations is growing as pressure increases on their livelihoods and living standards.

Syrians may enter Jordan with a passport and do not require a visa or residency permit. Under certain conditions they are permitted to reside in urban communities. Possession of a UNHCR registration card is needed for access to assistance and local services but refugees can easily lose their status and lose access to assistance if, for example, they move around the country. Many fail to register because of lack of information but mainly for security reasons and fear of detection by different factions fighting in Syria.

In Lebanon, a residence permit is required, valid for six months with the possibility of renewal for a further six months. However, subsequent extension is unaffordable by most refugees, effectively stripping them of their legal status. In Iraq, there is a vacuum in the 
statutory protection framework, and practice across the governorates is not uniform. These conditions limit freedom of movement and restrict access to work, services and housing. Palestine refugees leaving Syria who have already sought protection in neighbouring countries are particularly vulnerable, falling between highly restrictive residency conditions and the severely stretched resources of UNRWA, the UN agency mandated to assist them. In practical terms, since mid-2014 Turkey is the only one of the surrounding countries that will still allow entry to Palestinian refugees from Syria.

It appears that, despite the heavy emphasis of the humanitarian assistance programme on protection, many of those fleeing Syria are unaware of their rights and obligations. Those refugees with irregular status are increasingly marginalised and vulnerable. Access to cross the borders is the most pressing protection concern for refugees. Lebanon's periodic border closures - in response to cross-border violence and threats - and recent access restrictions put refugees at risk. Jordan and Lebanon regularly deny entry to Iraqi refugees from Syria and other groups without regular identity papers.

Some cases of arbitrary arrest and detention are reported in all three countries (though less evident in Lebanon). Palestinians have been particularly susceptible to arbitrary detention. Evidence suggests that secondary migration, as refugees move around the country of asylum or engage in circular migration to Syria, increases protection risks and intensifies household vulnerability as refugees lose their regular status. Of growing concern is the number of Syrians falling into irregular immigration status due to their inability to pay for renewal of their visas. ${ }^{6}$

Socio-economic factors and the lack of legal status increase refugees' susceptibility to a range of human rights abuses and vulnerabilities whether in camps or urban settings. Forced and early marriages have reportedly risen compared to the pre-crisis period and incidents of domestic violence, sexual and gender-based violence and violence against children are high. In urban settings, the possibility of eviction carries significant protection risks, especially as local authorities in some areas have started to crack down on refugees working informally. The longevity of the crisis has also accentuated the vulnerability of host communities, and tensions between refugee and host communities exacerbate protection risks.

\section{Responding to the development and protection challenges}

The challenge for humanitarian and development actors is to stabilise the precarious economic situation, forge a transition from assistance to development, promote economic development strategies which support host and refugee communities equitably, and reduce the potential for negative economic impacts to exacerbate domestic and regional tensions. At the same time there is the imperative to ensure and enhance a 'protective environment' for the refugees.

To develop a more secure evidence base on which to build better targeted interventions, a number of areas are a priority. At a strategic level more analysis is needed of how to better coordinate and align international humanitarian and development assistance with national development strategies in order to reduce the negative impacts and maximise development opportunities. Likewise, more analysis is needed on the structural impacts of the refugee crisis on regional trade and how these might be mitigated. At the micro-economic level, a more detailed understanding of labour-market dynamics under conditions of severe economic shock and severe over-supply of labour is needed. Deeper analysis of the interplay between livelihood insecurity and protection risks and the scope for community-based protection strategies would also help to enhance the protection objectives of RRP6.

To tackle the costs and impacts and the livelihood needs of the refugees and the host populations, a trial programme of locally 
targeted Quick Impact Projects (QIPs), in partnership with local authorities, the private sector and community-based organisations would be one way of delivering labourintensive projects in refugee-populated areas. This initiative could be supported by micro-enterprise finance mechanisms, cashfor-work programmes, and vocational and skills development training. It would be vital that these actions target vulnerable groups in both refugee and host communities and that the host populations are not financially disadvantaged by these initiatives.

More generally, a shift towards cash and market-based programming for livelihood assistance interventions would help to tackle the growing impoverishment of refugees and their hosts, alongside registration procedures that would allow refugees the right to work and establish businesses. These initiatives should be underpinned by improved household and livelihood vulnerability assessments and selection criteria.

\section{Tackling national-level impacts and} the fiscal stress on public services requires technical support to the national government finance and planning ministries to strengthen macro-economic development planning capacity for both short-term stabilisation and longerterm recovery and resilience.

\section{To safeguard and enhance the rights of refugees and embed a rights-based} orientation within the governance structures of the countries, programme capacity needs to be scaled up. This will require: ensuring that the practice of protection is made more consistent and effective; training and sensitising members of national security forces, including the police, and government officials on the concepts and practices of refugee protection; supporting the development of comprehensive strategies for refugee reception and protection; supporting local civil society groups working in the field of human rights and refugee protection; and conducting advocacy with relevant stakeholders for the rights of refugees.
Stronger legal benchmarks and better coverage of protection gaps in the national legal frameworks could be achieved by encouraging relevant authorities and agencies to: provide documents to Palestine and Iraqi refugees clarifying their legal status and enabling them to access services; locate and identify unregistered refugees, while being mindful of the sensitivity of this process; and desist from practices of deportation/ refoulement and arbitrary detention.

Finally there is the need to promote respect for refugees' rights, prevent violations and abuses towards refugees and reduce vulnerability, including by implementing community-based protection strategies and advocating for the involvement and inclusion of host communities in services and infrastructure provision for refugees.

\section{Roger Zetter roger.zetter@qeh.ox.ac.uk is} Emeritus Professor at the Refugee Studies Centre, University of Oxford. www.rsc.ox.ac.uk Héloïse Ruaudel heloise.ruaudel@gmail.com is a humanitarian policy and protection analyst.

\section{Our thanks to Sarah Deardorff-Miller, Eveliina Lyytinen and Cameron Thibos who conducted survey work on which this article and the main report are based.}

1. The RDPP is a three-year regional programme working
in Lebanon, Jordan and Iraq, supported by a platform of
humanitarian and development donors involving the European
Union, Denmark, Ireland, UK, the Netherlands and the Czech
Republic. It is led by Denmark.

2. The Syrian displacement crisis and a Regional Development and Protection Programme: Mapping and meta-analysis of existing studies of costs, impacts and protection was prepared for the Danish Ministry of Foreign Affairs. The full report is available at data.unhcr.org/syrianrefugees/download.php?id=4780

3. www.undp.org.lb/programme/pro-poor/poverty/ povertyinlebanon/molc/executive.htm

4. Lebanon, Economic and Social Impact Assessment of the Syrian Conflict, World Bank Report No. 81098-LB. September 2013 http://tinyurl.com/WB-EconomicSocialImpact-Leb

5. See 'Reframing Displacement Crises as Development Opportunities', paper prepared by Roger Zetter for the Displacement Solutions Initiative (DSI) Roundtable, Copenhagen, 2-3 April 2014

www.endingdisplacement.org/wp-content/uploads/2014/02/

Concept-note.pdf

6. See also article by Dalia Aranki and Olivia Kalis on p20-21. 